\title{
A new species of Varanus Merrem (Squamata: Varanidae) from the Pilbara region of Western Australia, with observations on sexual dimorphism in closely related species
}

\author{
KENNETH P. APLIN ${ }^{1}$, ALISON J. FITCH ${ }^{2,3}$ \& DENNIS J. KING ${ }^{4}$ \\ ${ }^{1}$ Australian National Wildlife Collection, CSIRO Sustainable Ecosystems, PO Box 284 Canberra, ACT, Austra- \\ lia; formerly Western Australian Museum, Francis Street, Perth, Western Australia 6000, Australia, \\ To whom correspondence should be addressed \\ ${ }^{2}$ School of Biological Sciences, Flinders University, GPO Box 2100, Adelaide, South Australia 5001, Australia; \\ ${ }^{3}$ Evolutionary Biology Unit, South Australian Museum, North Terrace, Adelaide, South Australia 5000, Australia \\ ${ }^{4}$ Deceased, formerly Research Associate of Western Australian Museum, Francis Street, Perth, Western Austra- \\ lia 6000, Australia
}

\section{Table of contents}

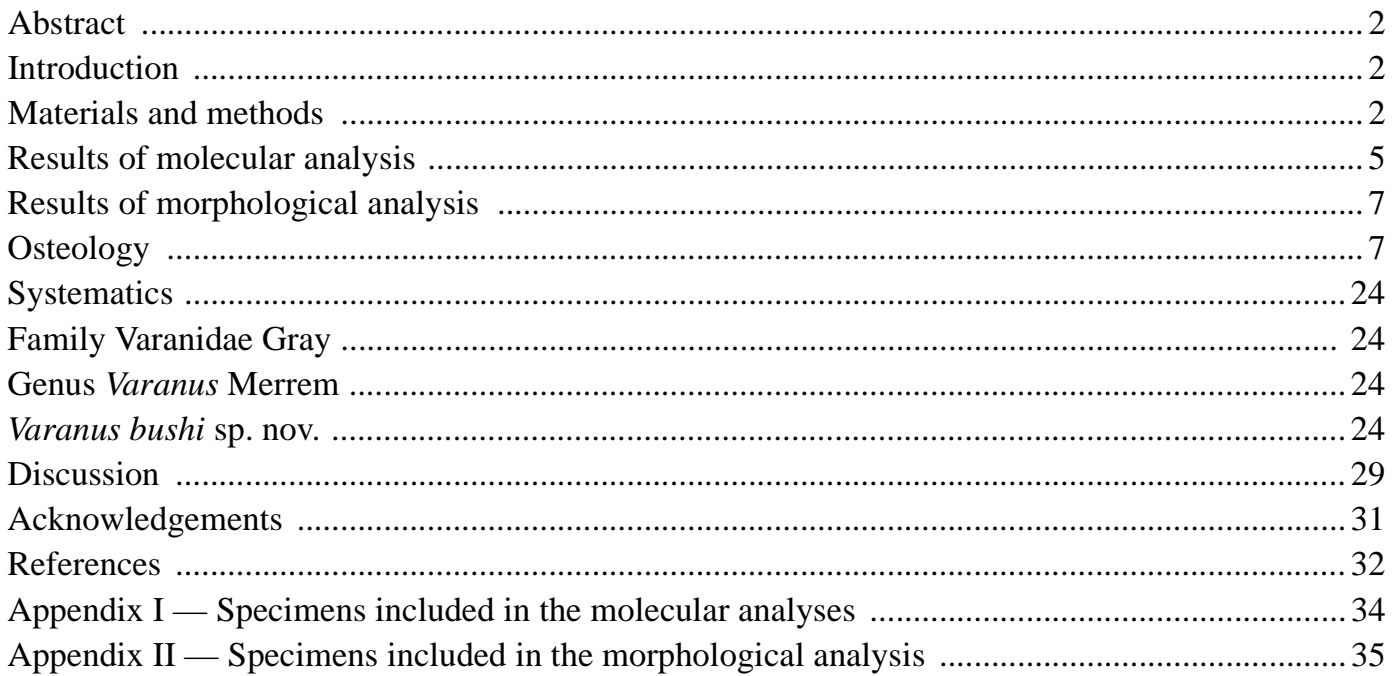

